\title{
Process improvement in cardiac surgery: Development and implementation of a reoperation for bleeding checklist
}

\author{
Gabriel Loor, MD, ${ }^{\mathrm{a}}$ Alessandro Vivacqua, MD, ${ }^{\mathrm{a}}$ Joseph F. Sabik III, MD, ${ }^{\mathrm{a}}$ Liang Li, PhD, ${ }^{\mathrm{b}}$ \\ Eric D. Hixson, PhD, MBA, ${ }^{\mathrm{c}}$ Eugene H. Blackstone, MD, ${ }^{\mathrm{a}, \mathrm{b}}$ and Colleen G. Koch, MD, MS, MBA ${ }^{\mathrm{d}, \mathrm{e}}$
}

Objective: High-performing health care organizations differentiate themselves by focusing on continuous process improvement initiatives aimed at enhancing patient outcomes. Reoperation for bleeding is an event associated with considerable morbidity risk. Hence, our primary objective was to develop and implement a formal operative checklist to reduce technical reasons for postoperative bleeding.

\begin{abstract}
Methods: From January 1, 2011, through June 30, 2012, 5812 cardiac surgical procedures were performed at Cleveland Clinic (Cleveland, $\mathrm{OH}$ ). A multidisciplinary team developed a simple, easy-to-perform hemostasis checklist based on the most common sites of bleeding. An extensive educational in-service was performed before limited, then universal, checklist implementation. Geometric charts were used to track the number of cases between consecutive reoperations for bleeding. We compared these before (phase 0 ) and after the first limited implementation phase (phase 1) and the universal implementation phase (phase 2) of the checklist.
\end{abstract}

Results: The average number of cases between consecutive reoperations for bleeding increased from 32 in phase 0 to 53 in both phase $1(P=.002)$ and phase $2(P=.01)$.

Conclusions: A substantial reduction in reoperation for bleeding cases followed implementation of a formalized hemostasis checklist. Our findings underscore the important influence of memory aids that focus attention on surgical techniques to improve patient outcomes in a complex, operative work environment. (J Thorac Cardiovasc Surg 2013;146:1028-32)

A continuous drive for improved quality of care through process improvement is a feature of high-performing health care systems. Institution of patient safety initiatives that strive to further reduce complications associated with complex operative procedures is the ideal. Patient safety checklists attempt to standardize critical and often complex processes to avoid error and improve outcomes. Although common in other industries, and a prominent feature of the early days of cardiac surgery, checklists have only recently been adopted as part of work flow processes in the health care environment. ${ }^{1}$ Benefits of checklist implementation in the health care setting include reduced patient morbidity, fewer errors, and improved team dynamics. ${ }^{2-8}$

From the Departments of Thoracic and Cardiovascular Surgery ${ }^{\mathrm{a}}$ and Cardiothoracic Anesthesia, ${ }^{\mathrm{d}}$ Heart and Vascular Institute; and the Department of Quantitative Health Sciences, ${ }^{\mathrm{b}}$ Medical Operations, Business Intelligence, ${ }^{\mathrm{c}}$ and Quality and Patient Safety Institute, ${ }^{\mathrm{e}}$ Research Institute, Cleveland Clinic, Cleveland, Ohio.

This study was supported, in part, by the Sheikh Hamdan bin Rashid Al Maktoum Distinguished Chair in Thoracic and Cardiovascular Surgery, held by Dr Sabik; and the Kenneth Gee and Paula Shaw, PhD, Chair in Heart Research, held by Dr Blackstone. These individuals played no role in the collection of data or analysis and interpretation of the data, and had no right to approve or disapprove publication of the finished manuscript.

Disclosures: Authors have nothing to report with regard to commercial support.

Received for publication Nov 21, 2012; revisions received April 19, 2013; accepted for publication May 9, 2013; available ahead of print July 22, 2013.

Address for reprints: Colleen G. Koch, MD, MS, MBA, Department of Cardiothoracic Anesthesia, Cleveland Clinic, 9500 Euclid Ave/Desk J4-331, Cleveland, OH 44195 (E-mail: kochc@ccf.org).

$0022-5223 / \$ 36.00$

Copyright (c) 2013 by The American Association for Thoracic Surgery http://dx.doi.org/10.1016/j.jtcvs.2013.05.043
Approximately $2 \%$ to $8 \%$ of patients return to the operating room for bleeding after admission to the intensive care unit after cardiac surgical interventions. ${ }^{9-13}$ Our investigation of these reoperations revealed that they were associated with increased morbidity, mortality, and resource use. ${ }^{14}$ Bleeding resulting from technical factors was the root cause of most $(>70 \%)$ of these reoperations; the remainder were related to coagulopathy.

We subsequently initiated a major focus on process improvement to reduce the need for reoperation due to technical factors. We hypothesized that increased attention to intraoperative hemostasis would reduce postoperative bleeding. Hence, our primary objective was to develop and implement a formal operative checklist to reduce technical reasons for postoperative bleeding.

\section{METHODS \\ Checklist Development}

Our prior work revealed that the most common sites for bleeding identified at reoperation were the mediastinum, sternum, internal thoracic artery bed, and coronary anastomosis sites. ${ }^{14}$ Multidisciplinary team meetings were held for checklist development with senior cardiac surgical staff, a cardiac surgery resident (G.L.) and fellow (A.V.), and anesthesiologists. The objective was to develop a simple, easy- to-perform checklist that could be integrated into the operative work flow (Figures 1 and 2). Simplicity, we believed, was key for trainees to transform the checklist into unconscious habits. Specifically, the checklist was devised to be used just before anticipated chest closure, which universally is performed by surgical trainees. Individual patient consent was waived by the Cleveland Clinic (Cleveland, Ohio) Institutional Review Board. 


\section{Abbreviations and Acronyms \\ $\mathrm{CABG}=$ coronary artery bypass grafting \\ WHO $=$ World Health Organization}

\section{Checklist Implementation}

Phase 0: Prechecklist. From January 1, 2011, through June 30, 2011, 2080 cardiac surgical procedures were performed at Cleveland Clinic. Before initiating the reoperation for bleeding checklist, a cardiac surgery resident (G.L.) and fellow (A.V.) were recruited as "champions" to provide other residents and fellows with formal educational sessions on morbidity related to reoperation for bleeding, desire to reduce its prevalence, and specifics of the checklist. Surgical nurse clinicians and operating room nurses were also in-serviced.

Phase 1: Limited implementation. From July 1, 2011, through October 31, 2011, 1296 cardiac surgical procedures were performed. The checklist was implemented in a single surgeon's operating room. More important, however, all cardiac surgical residents and fellows received the educational in-service before initiation of phase 1 because of surgical rotations and night call, which may have placed them in the phase 1 staff surgeon's rooms. After initiation of phase 1, feedback was obtained from the cardiac surgical team on ease of checklist use and suggestions for further improvement.

Phase 2: Universal implementation. After 4 months with the single surgeon in phase 1 , the checklist was universally implemented in all cardiac surgical operating rooms. From November 1, 2011, through June 30, 2012, 2436 cardiac surgical procedures were performed, all using the checklist.

The patient population over these time frames was consistent: phase 1, $\mathrm{n}=2080$, with $17 \%$ coronary artery bypass grafting (CABG), $52 \%$ isolated valve, $17.1 \% \mathrm{CABG} /$ valve combination, and $15 \%$ other cases; and phases 2 and $3, \mathrm{n}=3732$, with $15 \%$ CABG, $54 \%$ isolated valve, $17.3 \%$ $\mathrm{CABG} /$ valve combination, and $14 \%$ other cases.

\section{Measurement and Analysis}

We defined reoperation for bleeding as a return to the cardiac operating rooms for bleeding or tamponade after admission to the intensive care unit following the primary surgical procedure. The decision to reoperate was based on total chest tube drainage and its rate, hemodynamic status, and staff surgeon decision.

Prevalence of reoperation for bleeding was measured and presented on a geometric chart. Geometric charts are commonly used to track rare events and measure the number of cases between their consecutive occurrences; in our case, this was the number of cases between occurrences of reoperation for bleeding. ${ }^{15-17}$ Larger numbers on the geometric chart demonstrate better performance and fewer occurrences of these rare events. In this study, we counted the number of cases between consecutive cases of reoperation for bleeding and compared the averages before (phase 0 ) and after checklist implementation using a 2-sample, 2-sided $t$-test and the Wilcoxon rank-sum test. The primary analysis compared phase 0 with the entire postimplementation period (phases 1 and 2). A secondary analysis compared phase 0 with phase 2 (after universal implementation).

\section{RESULTS}

The geometric chart measuring the number of cases between consecutive reoperations for bleeding is shown in Figure 3, with larger numbers indicating process improvement (ie, fewer reoperations for bleeding).

After introduction of the checklist, the average number of cases between consecutive reoperations for bleeding increased from 32 in phase 0 to 53 in both phase 1 $(P=.002)$ and phase $2(P=.01)$. Continuous improvement was observed after universal implementation (phase 0 vs phase 2), with the average number of cases between consecutive reoperations for bleeding at 53 (Table 1). The effect was evident, however, immediately after limited implementation of the checklist (phase 1), likely because of the effect of having educated all surgical residents, fellows, and support staff about the checklist, even though they were not all rotating on the phase 1 surgeon's service.

There were 2080 cases before July 1, 2011 (before educational in-services and checklist implementation), with 65 reoperations for bleeding $(3.1 \%)$. After that date, there were 3732 cases, with 70 reoperations for bleeding $(1.9 \%)(P=.003)$.

\section{DISCUSSION}

We report a substantial reduction in reoperation for bleeding events after introduction of a hemostasis checklist. Reason ${ }^{18}$ describes checklists as "cognitive prostheses." Cognitive errors in clinical decision making are reported to be at the root of many mistakes. ${ }^{19}$ Stress, cognitive fatigue, and complex cases may influence proper decision making. ${ }^{1,20,21}$ The operative environment, in particular with trainees, is a milieu where high stress, fatigue, and need for quick decision making intersect, an ideal situation for checklists.

Unexpectedly, and perhaps because of both simplicity of the checklist and extent of education leading up to its implementation, reoperations for bleeding declined even during the time of checklist implementation for only 1 surgeon's cases (phase 1). Evidence suggests that both universal awareness via educational initiatives and increased emphasis on technical factors via the checklist led to fewer reoperations for bleeding. This is the desired effect for process improvement initiatives.

Checklists are meant to standardize often complex processes and serve as cognitive aids for error reduction. ${ }^{1}$ They consist of systematically rank-ordered criteria whose overarching goal is standardization and improved outcomes. Although checklists are increasingly used in health care, they have not been as widely adopted as in other industries, for cited reasons of limiting physician autonomy and difficulty in standardizing processes that are inherently variable. $^{1}$

Use of checklists in the surgical setting has been associated with reduced postoperative complications and mortality. Weiser and colleagues ${ }^{22}$ prospectively examined postoperative complications and hospital mortality before and after implementation of the 19-item World Health Organization (WHO) Surgical Safety Checklist in urgent operative cases. Significant reductions in both complications and mortality were reported after checklist implementation, with complications reduced from $18.4 \%$ to $11.7 \%$ and 


\section{Prior to Sternal Wires:}

- $\square$ Surgical Sites

$\cdot \square$ Cannulation sites

- $\square$ Proximals/ distals

- $\square$ Aortotomies/ atriotomies/ventriculotomies

- $\square$ Mediastinum

$\cdot \square$ Thymus

$\cdot \square$ Pericardium

- $\square$ Chest Wall

- $\square$ Mammary bed

\section{- $\square$ Sternum}

FIGURE 1. Reoperation for bleeding checklist.

mortality reduced from $3.7 \%$ to $1.4 \%$. In a general surgical setting of hospitals with high standards of care, de Vries and colleagues $^{6}$ also reported reductions in surgical complications and mortality associated with use of a surgical checklist. Haynes and colleagues ${ }^{4}$ reported a significant reduction in complications and mortality with use of the WHO checklist in a global population. Others have published similar results. $^{23}$

Checklists have been reported to provide benefits beyond traditional morbidity and mortality outcomes, including cost savings, improved team dynamics, and creation of a culture of safety. Semel and colleagues ${ }^{5}$ reported potential cost savings from reduced postoperative complications if the WHO checklist was instituted in the United States.

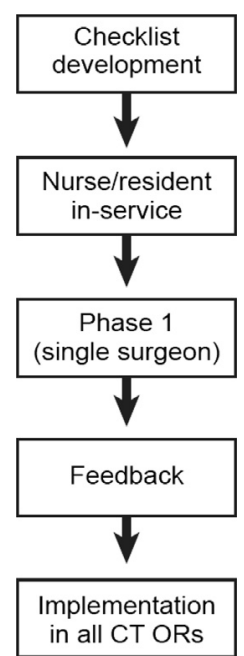

FIGURE 2. Process flow diagram for development and implementation of the reoperation for bleeding checklist. $C T$, Cardiothoracic; $O R$, operating room.

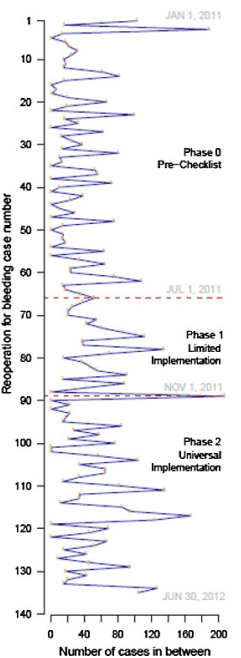

FIGURE 3. Geometric chart displaying the number of cases between reoperations for bleeding.

Calland and colleagues ${ }^{3}$ examined the utility and adaptability of procedural checklists in the surgical setting to test whether they can increase the frequency of safetycritical behaviors. The authors noted that checklists may be beneficial for error reduction, improved teamwork, and situational awareness in what they termed safety-critical processes, such as the complex operative environment. Their results showed similar patient outcomes with and without use of the checklists; however, they reported that the checklist intervention group had higher team-positive behaviors.

Buzink and colleagues ${ }^{24}$ examined the effect of implementing a checklist on equipment- and instrument-related events in the setting of laparoscopic cholecystectomies. They noted that the combination of integrated operating room systems and checklists might favorably influence operating room efficiency and surgical outcomes. Their results showed that this combined setting had a stronger effect than an integrated operating room alone. Use of the checklists also raised safety awareness among operating room team members.

Lingard and colleagues ${ }^{7}$ reported improvements in communication, with a decline in the number of communication failures per procedure after implementation of checkliststructured team meetings. Use of a 5-point Likert scale questionnaire before and after introduction of safety briefings resulted in positive staff attitudes toward these briefings. ${ }^{25}$

In a systematic review of safety checklists, Ko and colleagues ${ }^{26}$ suggested that they were associated with some improvements in patient safety; however, the results were not consistent. The authors suggested that variations in checklist design and individual settings created an inability to summarize trends across studies. Nevertheless, they noted a potential benefit in terms of improving protocol adherence. 
TABLE 1. Number of cases between consecutive reoperations for bleeding before and after checklist initiation

\begin{tabular}{|c|c|c|c|c|c|}
\hline Variable & Prechecklist & Postchecklist & $P$ value* & $\begin{array}{c}\text { After universal } \\
\text { implementation only }\end{array}$ & $P$ value* \\
\hline Dates & $1 / 1 / 2011-6 / 30 / 2011$ & $7 / 1 / 2011-6 / 30 / 2012$ & & $11 / 1 / 2011-6 / 30 / 2012$ & \\
\hline Total No. & 2080 & 3732 & & 2436 & \\
\hline \multicolumn{6}{|l|}{ Geometric statistic } \\
\hline Mean & $32 \pm 35$ & $53 \pm 43$ & $\begin{array}{c}P 1=.002 \dagger \\
P 2=.004\end{array}$ & $53 \pm 47$ & $\begin{array}{c}P 1=.011 \dagger \\
P 2=.033\end{array}$ \\
\hline Median (quartile 25, quartile 75 ) & $18(11,39)$ & $43(21,77)$ & $P<.001$ & $43(16,82)$ & $P=.009$ \\
\hline
\end{tabular}

\section{Clinical Implications}

Conley and colleagues ${ }^{27}$ reported that the success of surgical checklists was influenced by a hospital's ability to effectively implement them, along with educational efforts regarding their use and the rationale for their implementation. Education was necessary for getting "buy-in" from the surgical staff. Others who have reported on the benefits of checklists have also integrated key features for success, such as multidisciplinary teams and educational efforts. ${ }^{2}$

Educational in-services and clear communication on the importance of the initiative to patient care allowed for successful implementation of our checklist. Teams were multidisciplinary, which allowed for buy-in from those involved. We were cognizant of prior perceptions that might surface, such as "checklist fatigue" in the operative setting. We communicated that the clinical time involved averaged less than 5 minutes. Several other investigators have highlighted key aspects of checklist development, along with suggestions for piloting the checklist before more widespread implementation. ${ }^{28,29}$

The Accreditation Council for Graduate Medical Education has specific recommendations for practice-based learning competencies that involve trainee engagement in quality improvement methods aimed at implementing initiatives for practice improvement. Our thoracic and cardiovascular surgical resident (G.L.) and fellow (A.V.) spearheaded the educational in-service and implementation and feedback sessions throughout the course of the process improvement initiative. They were an integral part of project development and learned to develop and implement process improvement plans, understand use of process control and Pareto and geometric charts, engage multidisciplinary teams, and obtain and receive feedback for the duration of the improvement initiative.

\section{Study Limitations}

Reoperation for bleeding necessitating a return to the cardiac operating room for bleeding or tamponade was based on total chest tube drainage and its rate, hemodynamic status, and staff surgeon decision. We did not have information on the specific amount of chest tube drainage; however, the cardiac surgical attending surgeons and intensive care unit care teams were consistent throughout the process improvement initiative. Our institution does not have a rigorous or standardized algorithm to aid decision making on whether a patient should be returned to the operating room for bleeding. In addition, we do not capture the actual amount of chest tube drainage in our electronic medical record. Our goal was not to measure blood product use for the duration of the study period, but rather to focus on intraoperative practices that could reduce the need for reoperation for bleeding.

\section{CONCLUSIONS}

We observed a significant reduction in reoperation for bleeding after implementing a formalized surgical checklist. Our findings underscore the important influence of memory aids that focus attention on surgical techniques to improve patient outcomes in our complex work environment.

\section{References}

1. Hales BM, Pronovost PJ. The checklist-a tool for error management and performance improvement. J Crit Care. 2006;21:231-5.

2. Wolff AM, Taylor SA, McCabe JF. Using checklists and reminders in clinical pathways to improve hospital inpatient care. Med J Aust. 2004;181:428-31

3. Calland JF, Turrentine FE, Guerlain S, Bovbjerg V, Poole GR, Lebeau K, et al. The surgical safety checklist: lessons learned during implementation. Am Surg. 2011;77:1131-7.

4. Haynes AB, Weiser TG, Berry WR, Lipsitz SR, Breizat AH, Dellinger EP, et al. A surgical safety checklist to reduce morbidity and mortality in a global population. N Engl J Med. 2009;360:491-9.

5. Semel ME, Resch S, Haynes AB, Funk LM, Bader A, Berry WR, et al. Adopting a surgical safety checklist could save money and improve the quality of care in U.S. hospitals. Health Aff (Millwood). 2010;29:1593-9.

6. de Vries EN, Prins HA, Crolla RM, den Outer AJ, van Andel G, van Helden SH, et al. Effect of a comprehensive surgical safety system on patient outcomes. N Engl J Med. 2010;363:1928-37.

7. Lingard L, Regehr G, Orser B, Reznick R, Baker GR, Doran D, et al. Evaluation of a preoperative checklist and team briefing among surgeons, nurses, and anesthesiologists to reduce failures in communication. Arch Surg. 2008;143:12-7; discussion 18.

8. van Klei WA, Hoff RG, van Aarnhem EE, Simmermacher RK, Regli LP, Kappen TH, et al. Effects of the introduction of the WHO "Surgical Safety Checklist" on in-hospital mortality: a cohort study. Ann Surg. 2012;255:44-9.

9. Mehta RH, Sheng S, O'Brien SM, Grover FL, Gammie JS, Ferguson TB, et al. Reoperation for bleeding in patients undergoing coronary artery bypass surgery: incidence, risk factors, time trends, and outcomes. Circ Cardiovasc Qual Outcomes. 2009;2:583-90.

10. Hall TS, Brevetti GR, Skoultchi AJ, Sines JC, Gregory P, Spotnitz AJ. Re-exploration for hemorrhage following open heart surgery differentiation on the causes of bleeding and the impact on patient outcomes. Ann Thorac Cardiovasc Surg. 2001;7:352-7. 
11. Karthik S, Grayson AD, McCarron EE, Pullan DM, Desmond MJ. Reexploration for bleeding after coronary artery bypass surgery: risk factors, outcomes, and the effect of time delay. Ann Thorac Surg. 2004;78:527-34; discussion 34.

12. Dacey LJ, Munoz JJ, Baribeau YR, Johnson ER, Lahey SJ, Leavitt BJ, et al Northern New England Cardiovascular Disease Study Group. Reexploration for hemorrhage following coronary artery bypass grafting: incidence and risk factors. Arch Surg. 1998;133:442-7.

13. Choong CK, Gerrard C, Goldsmith KA, Dunningham H, Vuylsteke A. Delayed re-exploration for bleeding after coronary artery bypass surgery results in adverse outcomes. Eur J Cardiothorac Surg. 2007;31:834-8.

14. Vivacqua A, Koch CG, Yousuf AM, Nowicki ER, Houghtaling PL, Blackstone EH, et al. Morbidity of bleeding after cardiac surgery: is it blood transfusion, reoperation for bleeding, or both? Ann Thorac Surg. 2011;91:1780-90.

15. Benneyan JC. Number-between g-type statistical quality control charts for monitoring adverse events. Health Care Manag Sci. 2001;4:305-18.

16. Benneyan JC. Performance of number-between g-type statistical control charts for monitoring adverse events. Health Care Manag Sci. 2001;4:319-36.

17. Kaminsky FC, Benneyan JC, Davis RD, Burke RJ. Statistical control charts based on a geometric distribution. J Qual Technol. 1992;24:63-9.

18. Reason J. Human Error. Cambridge, UK: Cambridge University Press; 1999.

19. Croskerry P. Cognitive forcing strategies in clinical decisionmaking. Ann Emerg Med. 2003;41:110-20.

20. Sexton JB, Thomas EJ, Helmreich RL. Error, stress, and teamwork in medicine and aviation: cross sectional surveys. BMJ. 2000;320:745-9.
21. Hockey GR, Sauer J. Cognitive fatigue and complex decision making under prolonged isolation and confinement. Adv Space Biol Med. 1996;5:309-30.

22. Weiser TG, Haynes AB, Dziekan G, Berry WR, Lipsitz SR, Gawande AA. Effect of a 19-item surgical safety checklist during urgent operations in a global patient population. Ann Surg. 2010;251:976-80.

23. Askarian M, Kouchak F, Palenik CJ. Effect of surgical safety checklists on postoperative morbidity and mortality rates, Shiraz, Faghihy Hospital, a 1-year study. Qual Manag Health Care. 2011;20:293-7.

24. Buzink SN, van Lier L, de Hingh IH, Jakimowicz JJ. Risk-sensitive events during laparoscopic cholecystectomy: the influence of the integrated operating room and a preoperative checklist tool. Surg Endosc. 2010;24:1990-5.

25. Ali M, Osborne A, Bethune R, Pullyblank A. Preoperative surgical briefings do not delay operating room start times and are popular with surgical team members. J Patient Saf. 2011;7:139-43.

26. Ko HC, Turner TJ, Finnigan MA. Systematic review of safety checklists for use by medical care teams in acute hospital settings-limited evidence of effectiveness. BMC Health Serv Res. 2011;11:211.

27. Conley DM, Singer SJ, Edmondson L, Berry WR, Gawande AA. Effective surgical safety checklist implementation. J Am Coll Surg. 2011;212:873-9.

28. Hales B, Terblanche M, Fowler R, Sibbald W. Development of medical checklists for improved quality of patient care. Int J Qual Health Care. 2008;20:22-30.

29. Verdaasdonk EG, Stassen LP, Widhiasmara PP, Dankelman J. Requirements for the design and implementation of checklists for surgical processes. Surg Endosc. 2009;23:715-26. 